\title{
Bilateral Milian's Ear Sign of Erysipelas
}

\author{
Kiyozumi Suzuki ${ }^{1-3}$ and Hiromasa Otsuka ${ }^{2,3}$
}

Key words: erysipelas, ear, bilateral, Milian's ear sign

(Intern Med 56: 2381-2382, 2017)

(DOI: 10.2169/internalmedicine.8694-16)

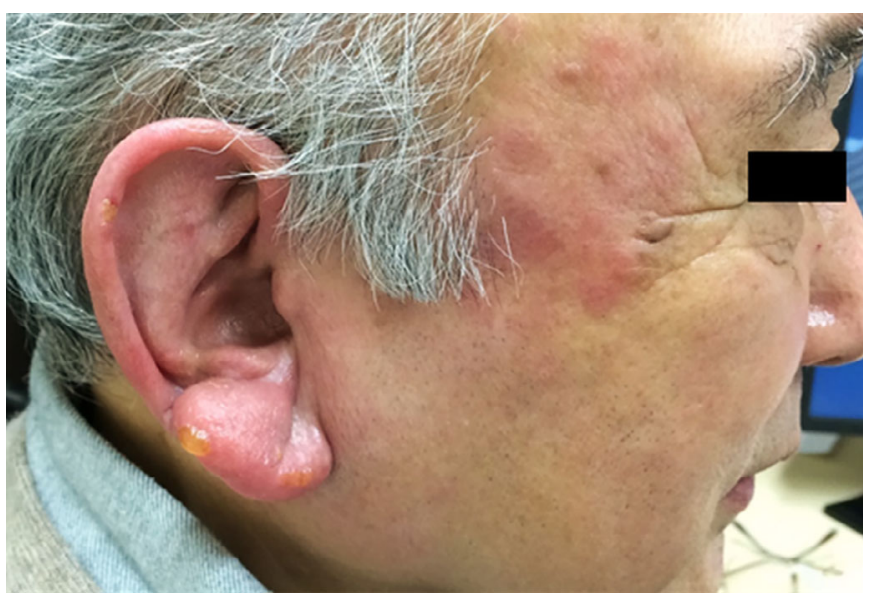

Picture 1.

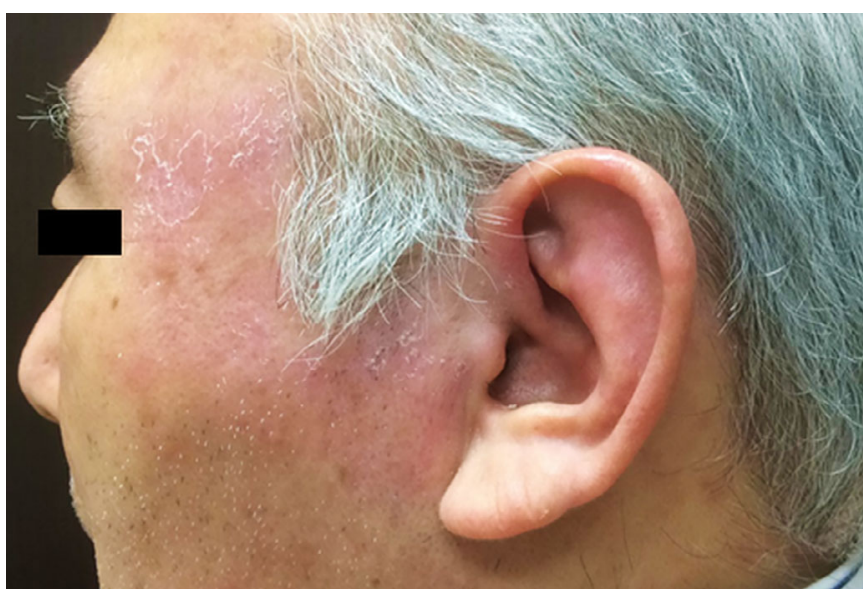

Picture 3.

A 76-year-old man presented with fever, and pain in his right ear. Physical examination revealed tender edematous, erythema, and a few vesicles of the right ear, along with facial involvement (Picture 1, 2). Laboratory examination

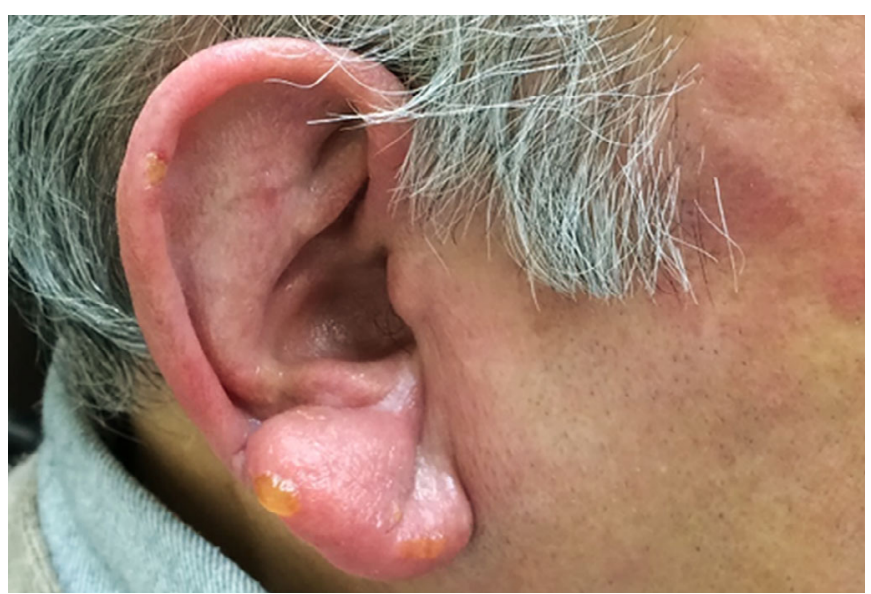

Picture 2.

showed neutrophilic leukocytosis. The next day, his left ear and face showed a tender light-colored erythema (Picture 3). After treatment with intravenous ceftriaxone, his symptoms fully resolved. Serum IgM using an enzyme immunoassay for both varicella-zoster virus and herpes simplex virus was negative. Finally, a clinical diagnosis of bilateral ear erysipelas was made.

Erysipelas is a common infection involving the upper dermis and lymphatics, whereas cellulitis involves the deeper dermis and subcutaneous fat (1). Ear involvement is called Milian's ear sign, and it is a feature distinguishing erysipelas from cellulitis, because the pinna has no deeper dermis and subcutaneous tissue (2). Bilateral ear erysipelas is rare, but it should be considered in the differential diagnosis when encountering patients presenting with red ears.

The authors state that they have no Conflict of Interest (COI).

\footnotetext{
${ }^{1}$ Department of General Medicine, Juntendo University Faculty of Medicine, Japan, ${ }^{2}$ Division of General Medicine, Department of Internal Medicine, Nihon University School of Medicine, Japan and ${ }^{3}$ Department of Emergency Room and General Medicine, Ageo Central General Hospital, Japan

Received: December 11, 2016; Accepted: January 17, 2017; Advance Publication by J-STAGE: August 10, 2017

Correspondence to Dr. Hiromasa Otsuka, hiromasa02k@gmail.com
} 


\section{References}

1. Bonnetblanc JM, Bédane C. Erysipelas: recognition and management. Am J Clin Dermatol 4: 157-163, 2003.

2. Madke B, Nayak C. Eponymous signs in dermatology. Indian Der- matol Online J 3: 159-165, 2012.

The Internal Medicine is an Open Access article distributed under the Creative Commons Attribution-NonCommercial-NoDerivatives 4.0 International License. To view the details of this license, please visit (https://creativecommons.org/licenses/ by-nc-nd/4.0/).

(C) 2017 The Japanese Society of Internal Medicine Intern Med 56: 2381-2382, 2017 